\title{
Zaznave učiteljev začetnikov o svojih mentorjih in sodelovanju $\mathrm{z}$ njimi
}

Maja Šebjanič Oražem

\section{Uvod}

\section{Poklicna identiteta}

Poklicna identiteta je sestavina celotne posameznikove identitete, ki nastaja in se oblikuje ob vključitvi v delo in procese dela. Ob tem je posameznik soočen $\mathrm{z}$ dvema procesoma:

- posameznik mora doseči prepoznanje institucije in posameznikov, s katerimi vstopa v interakcijo;

- identiteto mora ponotranjiti (Muršak idr., 2011).

»Poklicna identiteta torej izvira iz posameznikovih dejavnosti in socialnih odnosov med različnimi akterji.« (Muršak idr., 2011: 21, po Autret, 2009) Pri oblikovanju poklicne identitete posameznik prilagaja in ustrezno zunanjim pogojem (tj. razumevanju skupine in doseganju rezultatov) oblikuje lastno predstavo o sebi, samointerpretacijo. Gre za proces t. i. konverzije, v okviru katerega mora posameznik ustrezno izoblikovati takšno vizijo sebe in sveta, ki mu omogoča sprejem vloge in opravljanje dela, dejavnosti ali poklica. Posameznik spremeni sebe in ponotranji ideje »na štirih področjih:

- $\quad$ kaj in kako posameznik razume svoje delo;

- $\quad$ kaj bi morala biti njegova vloga;

- kakšna je ustrezna in zaželena kariera glede na prvi dve točki; in 
- $\quad$ kakšen naj bi v resnici bil sam kot nosilec poklica« (Muršak idr., 2011: 21).

$\mathrm{V}$ procesu identifikacije se posameznik uskladi s pričakovanji svoje socialno-poklicne referenčne skupine, kar pripelje do občutka pripadnosti s ponotranjanjem norm in legitimnih modelov te referenčne skupine. Referenčna skupina je v učiteljskem poklicu videna kot skupnost, »ki je socialno homogena in integrirana, $\mathrm{z}$ močno stopnjo identifikacije med člani, kar omogoča tudi stabilne socialne odnose. Posameznik doživlja sebe kot del celote, socialnega korpusa, ki mu pripada in od katerega tudi pričakuje ustrezno socialno podporo in zaščito« (ibid.: 22).

Ob vsem tem se dogaja še proces simbolne vključitve posameznika v skupino oz. t. i. iniciacije, saj ni dovolj le, da posameznik spozna in se nauči opravljati določeno delo in se z njim tako ali drugače poistoveti, ponotranji norme in načine vedenja. Posameznik mora biti tudi ustrezno iniciiran, bolj ali manj formalno vpeljan v družbeno vlogo, priznan kot predstavnik te vloge/poklica v očeh sodelavcev pa tudi v očeh drugih članov skupnosti. Ključno vlogo pri tem ima obdobje prehoda iz šolanja v zaposlitev (ibid.) oz. v učiteljskem poklicu obdobje uvajanja v pedagoški poklic.

\section{Oblikovanje poklicne identitete učitelja}

Poklicna identiteta učitelja »vsebuje učiteljevo znanje o sebi v različnih pedagoških situacijah in z njimi povezanimi socialnih odnosih" (Razdevšek Pučko in Juriševič, 2010: 13), oblikuje se »v različnih fazah in je nepretrgan proces, ki se začne že pred neposrednim vstopom ali začetkom dela na določenem poklicnem področju « (Muršak idr., 2011: 24). Gre za prvo obdobje oblikovanja poklicne identitete oz. t. i. vnaprejšnjo ali anticipatorno poklicno socializacijo. Proces vnaprejšnje identifikacije s poklicno vlogo je pomemben, saj že ob vstopu v poklic vnaprej zaznamuje posameznikov poklicni razvoj. V učiteljskem poklicu je vnaprejšnja socializacija v veliki meri vodena v okviru dodiplomskega izobraževanja, ki v okviru pedagoške pra$\mathrm{kse}^{\mathrm{I}}$ omogoča bodočim učiteljem (bolj kot pripravo na delo) pridobivanje izkušenj in srečevanje s člani poklicne skupine, ki ji bodo bodoči učitelji pripadali. »Kolikor bolj so te izkušnje in socialni stiki reflektirani in kolikor več je priložnosti, da si prihodnji učitelji take izkušnje pridobijo, toliko manjši bo vstopni šok oz. toliko manjša bo stopnja vstopne frustracije, ki nastane, ko posameznik vstopi v referenčno skupino in proces konverzije, 
ki je pogoj oblikovanja njegove identitete. Napetost, ki nastane med (vnaprejšnjo) podobo, predstavo o učitelju in dejansko (prvo) izkušnjo, bo tem manjša, kolikor bolj bomo prihodnjega učitelja že pred samostojnim vstopom $\mathrm{v}$ razred opremili $\mathrm{z}$ ustreznimi izkušnjami in vplivali na njegovo samorazumevanje.« (ibid.: 25)

Drugo obdobje pri oblikovanju poklicne identitete učitelja predstavlja začetek pedagoškega dela posameznika oz. obdobje uvajanja $\mathrm{v}$ pedagoški poklic. »To je obdobje, ko lahko s sistemom stalnega strokovnega izpopolnjevanja podpiramo in nadgrajujemo učiteljev strokovni razvoj« (prav tam: 130) na področju (temeljnih) strokovnih kompetenc in splošnih pedagoških kompetenc. V tem obdobju stroka loči tri faze (Muršak idr., 2011: 131):

- $\quad$ vstop v poklicno kulturo - začne se lahko že v času šolanja in vodenega uvajanja $\mathrm{v}$ pedagoški poklic (prvega srečanja s poklicnim delom, $\mathrm{z}$ realno referenčno skupino, pogoji, vrednotami in normami), ki ga spremlja vse večja identifikacija s poklicno vlogo;

- umestitev in soočenje $-\mathrm{z}$ razhajanjem med idealnim, zamišljenim modelom in stvarnim, dejanskim modelom, poleg referenčne skupine dobi posameznik tudi povratno informacijo o sebi in svoji vlogi;

- končna konverzija ali ponotranjenje poklicne vloge - pomeni interiorizacijo pravil, norm, vzorcev vedenja, načinov delovanja in pedagoške komunikacije, ustalitev modelov ravnanja, samorazumevanja in samoreprezentacije.

Gre torej za kontinuiran in progresiven proces $\mathrm{v}$ razvoju poklicnega življenja učitelja. Poklicna identiteta kot taka pomeni postopno oblikovanje oziroma konstrukcija znanja, ki ga učitelj ustvarja o sebi (Razdevšek Pučko in Juriševič, 2010) med uvajanjem v pedagoški poklic.

\section{Dejavniki, ki vplivajo na poklicno identiteto učitelja}

C. Razdevšek Pučko in M. Juriševič (2010: 14) po Stoutu (2001) povzemata tri skupine dejavnikov, ki vplivajo na poklicno identiteto učitelja:

- $\quad$ »učiteljevi dinamični odnosi z drugimi, še posebej znotraj referenčne skupine;

- spremembe in kulturna raznovrstnost šol in 
- $\quad$ inovacije in različni reformni posegi v šolo, ki vplivajo na naravo izobraževalnega okolja (na primer uporaba novih tehnologij, novi učni načrti)«.

Kot izjemno pomemben oziroma najmočnejši dejavnik, ki vpliva na razvoj poklicne identitete učitelja, avtorici (Ko Smith v Razdevšek Pučko in Juričevič, 2010) navajata opazovanje šolske prakse ter prvo leto poučevanja in intenzivnost teh izkušenj. Zaradi tega je izjemno pomembno ozavestiti in utrditi poklicno naravnanost $\mathrm{v}$ prvih letih študija, ko so bodoči učitelji najbolj občutljivi in dovzetni za pragmatične nasvete izkušenih učiteljev.

\section{Profesionalni razvoj učitelja začetnika}

Profesionalni razvoj učitelja je proces pomembnega vseživljenjskega učenja, ki vključuje učiteljevo osebno, poklicno in socialno dimenzijo. Pomeni učiteljevo napredovanje $\mathrm{v}$ smeri kritičnega, neodvisnega in odgovornega odločanja in ravnanja (Javornik Krečič, 2008: 16; Valenčič Zuljan, 2001: 127). Kontinuiran profesionalni razvoj učitelja se začne že z izobraževanjem na fakulteti, najintenzivnejši pa postane $\mathrm{z}$ vstopom $\mathrm{v}$ poklic oz. $\mathrm{z}$ uvajanjem v delo. Če učitelj prepozna pomembnost profesionalnega razvoja že v obdobju uvajanja v pedagoški poklic, nadaljuje s stalnim strokovnim izpopolnjevanjem in nadaljnjim izobraževanjem (Zelena knjiga ..., 2001: 15).

Uvajanje v pedagoški poklic (pripravništvo) je torej prvo obdobje v profesionalnem oz. strokovnem razvoju učitelja in je najbolj občutljivo in odločilno v učiteljevi (poklicni) socializaciji (Javornik Krečič 20o8: 38) ter hkrati pomemben dejavnik profesionalnega razvoja učitelja začetnika, saj kontekst uvajanja $\mathrm{v}$ poklic in kakovost mentorja vplivata na napredovanje in profesionalni razvoj učitelja začetnika (Valenčič Zuljan idr., 2007a: 8-9).

\section{Mentor}

Mentor kot eden najpomembnejših dejavnikov uvajanja začetnika $\mathrm{v}$ pedagoški poklic je zaupanja vreden vodja ali prijatelj ter pozitiven vzornik (Mass Mentoring Partnership, 2013). Je oseba, ki začetnika vodi, usmerja, spodbuja, mu daje naloge, ga postavlja pred nove izzive in mu organizira možnost za pridobivanje izkušenj ter svetuje v delovnih situacijah (Koki, 1997). Po drugi strani mu tudi pomaga, olajša delo in učenje ter ga varuje pred napakami in drugimi posledicami neizkušenosti (Valenčič Zuljan idr., 2007a: 11; Valenčič Zuljan idr., 2007b: 125) ter je model poučevanja (Puklek Levpušček, 2007: 50). 
Mentor s svojo vlogo najbolj neposredno vpliva na razvoj bodočega učitelja in mora služiti kot (zgleden) model učiteljeve vloge v izobraževanju (Javornik Krečič, 2008; Koki, 1997; Rebolj 2006). Za svoje delo oz. uspešno opravljanje te pomembne vloge potrebuje ustrezno znanje in usposobljenost za svoje delo (poučevanje) ter ustrezne sposobnosti oz. kompetence za opravljanje vloge mentorja (Muršak idr., 2011: 49; Rebolj, 2006: 166; Valenčič Zuljan idr., 2011: 44).

\section{Značilnosti mentorja}

Mentor naj bi svojega varovanca (učitelja začetnika/pripravnika) spodbujal, se $z$ njim pogovarjal, ga usmerjal, sistematično opazoval in analiziral njegovo delo ter mu posredoval konstruktivno povratno informacijo o svojih opažanjih ipd. (Muršak idr., 2011: 51; Rebolj, 2006: 165; Valenčič Zuljan idr., 2007a: 11-12). Odgovoren je tudi za socializacijo mentoriranca v delovno okolje, organizacijo oz. šolo in poklic (Mullen, 2012: 7) in je viden kot udeleženec, čigar izkušnje, opazovanja in interpretacije so visoko cenjene ter pomagajo drugim razumeti razmerje med poučevanjem in učenjem (Parker-Katz in Bay, 2008: 1260).

\section{Naloge mentorja}

Mentor (v Sloveniji) po Pravilniku o pripravništvu strokovnih delavcev na področju vzgoje in izobraževanja (19. člen) opravlja naslednje naloge:

- $\quad$ "pripravi program pripravništva;

- $\quad$ svetuje pripravniku pri izvajanju nalog, ki jih mora izvesti v skladu s programom;

- $\quad$ sodeluje z ravnateljem vrtca oziroma šole, šolsko svetovalno službo, ustreznimi strokovnimi aktivi in drugimi strokovnimi organi vrtca oziroma šole, pri organizaciji in izvedbi nalog programa pripravništva;

- $\quad$ svetuje pripravniku pri načrtovanju, organizaciji in izvedbi praktičnih nastopov oziroma drugih oblik neposrednega vzgojno-izobraževalnega dela, ki ga spremlja in analizira ter pripravniku sproti posreduje povratne informacije;

- $\quad$ spremlja pripravnikove priprave in njegov dnevnik glede na potek izvedbe ostalih delov programa pripravništva; 
- izdela poročilo o pripravnikovi usposobljenosti za samostojno opravljanje dela in pripravi oceno praktičnih nastopov, ki jih pripravnik uveljavlja za pristop k strokovnemu izpitu v skladu s pravilnikom, ki ureja strokovni izpit na področju vzgoje in izobraževanja;

- ob zaključku pripravništva $\mathrm{v}$ sodelovanju $\mathrm{z}$ ravnateljem poroča o spremljavi pripravništva;

- $\quad$ opravlja druge naloge, povezane s programom pripravništva.«

\section{Vloge mentorja v obdobju uvajanja v pedagoški poklic}

Iz nalog, ki jih ima mentor, njegovih (osebnostnih) značilnosti in kompetenc izhaja naslednjih šest vlog mentorja: model, informator, svetovalec, ocenjevalec, organizator in povezovalec (Muršak idr., 2011: 52; Rebolj, 2006: 167).

Mentorjeva vloga modela se nanaša na kakovosten prikaz načina poučevanja, ki naj bi bilo čim bolj raznoliko in inovativno.

Kot informator bi moral mentor pripravnika informirati o učencih, razredih, šoli, kolektivu, izboru učnih metod in pripomočkov, o formalnih in neformalnih normah ter pričakovanjih.

Svojo vlogo svetovalca naj bi mentor izpolnjeval med pripravo učnih ur, zlasti pa po opravljenih nastopih s kakovostno povratno informacijo preko natančne analize.

Vloga mentorja kot ocenjevalca se nanaša tako na opravljene nastope kot tudi na uvajanje pripravnika v kriterije samoocenjevanja.

Kot organizator mentor svojemu mentorirancu pripravi program pripravništva in mu časovno ter organizacijsko razporeja njegove dejavnosti in obveznosti.

Mentor bi moral biti tudi povezovalec po eni strani praktičnih izkušenj s teoretičnim znanjem, po drugi strani pa povezovalec med pripravnikom in šolskim kolektivom, da bi se njegov mentoriranec čim bolje vključil v šolsko okolje (Rebolj, 20o6: 167, po Marentič Požarnik, 1989). 


\section{Metoda}

$\mathrm{V}$ proučevanje uresničevanja ciljev uvajanja učitelja začetnika ${ }^{2} \mathrm{v}$ pedagoški poklic z vidika oblikovanja poklicne identitete učitelja slovenščine je bil usmerjen del raziskave na temo Vloga obdobja pripravništva pri pridobivanju kompetenc za poučevanje slovenščine. Raziskava je potekala v okviru doktorskega študija (na FF UL, pod mentorstvom red. prof. dr. Bože Krakar Vogel). V raziskavi je sodelovalo 72 učiteljev začetnikov in 60 mentorjev učiteljem začetnikom.

Od 72 anketiranih pripravnikov jih je 51 (70,8 \%) opravljalo volontersko pripravništvo, $21(29,2 \%)$ pa so ga imeli plačanega. Dobra polovica anketiranih (44 oziroma 61,1 \%) je pripravništvo opravljala v osnovni šoli, dobra četrtina (20 oziroma 27,8 \%) pa v gimnaziji. Po štirje anketirani $(5,6 \%)$ so pripravništvo opravljali v poklicni ali strokovni šoli oziroma srednji tehniški šoli.

Kot inštrument za raziskovanje smo uporabili anketni vprašalnik, ki smo ga za namene raziskave na podlagi strokovne in znanstvene literature o kompetencah učitelja slovenščine sestavili s pomočjo mentorice. Sestavili smo dva različna anketna vprašalnika - enega za učitelje začetnike/pripravnike in enega za njihove mentorje. Raziskava pa je zajemala tudi analizo sistemskih aktov in ostalih predpisov s področja uvajanja $v$ pedagoški poklic, tj. pripravništva.

Ob raziskovanju omenjene teme smo se osredotočili zlasti na proces mentoriranja, ki je ključen pri oblikovanju poklicne identitete učitelja začetnika, in si v ta namen zastavili naslednja raziskovalna vprašanja:

- Kakšna so bila njihova začetna pričakovanja do mentorja?

- Kako pripravniki ocenjujejo njihovo sodelovanje z mentorjem?

- Kako pripravniki ocenjujejo usposobljenost svojega mentorja za opravljanje ključnih nalog, ki jih imajo mentorji v času uvajanja učitelja začetnika $v$ pedagoški poklic (mentor kot model, vključevalec $\mathrm{v}$ šolsko kulturo, sponzor, podpornik in izobraževalec)?

- Kako ocenjujejo mentorjeve profesionalne kompetence?

2 V naši raziskavi smo jih imenovali pripravniki, saj je takrat veljavna slovenska zakonodaja učitelja začetnika, ki po zaključenem univerzitetnem izobraževanju vstopa v pedagoški poklic pod vodstvom usposobljenega učitelja praktika (pripravniškega mentorja), imenovala $\mathrm{z}$ izrazom pripravnik. V prispevku smo terminologijo poenotili s strokovno literaturo in pripravnika imenujemo učitelj začetnik. 
Ob tem smo na podlagi analize strokovne literature in predhodne raziskave (glej Šebjanič 2014) predpostavljali naslednje:

- Učitelji začetniki so od mentorja pričakovali, da jim bo mentor pomagal pri spoznavanju dela učitelja slovenščine in jih opozoril na "pasti« oziroma težave pri poučevanju.

- Učitelji začetniki sodelovanje z mentorjem ocenjujejo kot dobro.

- Mentorjevo usposobljenost za opravljanje nalog mentorja učitelji začetniki ocenjujejo kot dobro.

- Učitelji začetniki mentorjeve profesionalne kompetence ocenjujejo kot odlične.

\section{Rezultati}

\section{Učitelji začetniki o pričakovanjih in sodelovanju z mentorjem}

K oblikovanju poklicne identitete učitelja začetnika pomembno prispevajo pričakovanja učiteljev začetnikov do mentorjev in ocena njihovega sodelovanja $\mathrm{z}$ mentorjem. V Tabeli 9 so prikazana njihova pričakovanja, pri čemer so anketiranci imeli pri odgovarjanju na vprašanja na voljo več izbir.

Tabela 9: Začetna pričakovanja učiteljev začetnikov do mentorja

Pričakoval sem, da mi bo mentor pomagal pri spoznavanju šole, učencev in kolektiva.

Pričakoval sem, da mi bo mentor pomagal pri spoznavanju dela učitelja slovenščine.

Pričakoval sem, da mi bo mentor pomagal pri načrtovanju pouka oziroma nastopov.

$17 \quad 14,4$

Pričakoval sem, da bo mentor $\mathrm{z}$ mano delil svoje izkušnje.

Pričakoval sem, da me bo mentor opozoril na "pasti« oziroma težave pri poučevanju.

Pričakoval sem, da mi bo mentor svetoval pri izbiri strokovne literature.

1311,0

Drugo:

Šolo sem poznal, ker sem jo obiskoval in je v mojem domačem kraju. Mentor je bil tudi moj učitelj.

Pričakoval sem, da bo mentor bolj prijatelj.

*Zaradi zaokroževanja vsota strukturnih odstotkov ni ıoo,o, ampak 99,9. 
24 učiteljev začetnikov (20,3 \%) je od svojega mentorja pričakovalo, da jim bo pomagal pri spoznavanju dela učitelja slovenščine, nekoliko manj (22 oziroma 18,6 \%) pa jih je pričakovalo, da bo mentor z njimi delil svoje izkušnje oziroma da jih bo opozoril na težave pri poučevanju, torej jim na nek način prihranil negativne izkušnje. Da jim bo mentor pomagal pri spoznavanju šole, učencev in kolektiva, je pričakovalo 18 anketiranih učiteljev začetnikov (15,3\%). S 17 (14,4 \%) odgovori sledi pričakovanje anketirancev, da jim bo mentor pomagal pri načrtovanju pouka oziroma nastopov, $s$ $13(11,0 \%)$ pa, da jim bo mentor svetoval pri izbiri strokovne literature. Pod drugo sta $2(1,7 \%)$ anketiranca odgovorila, da sta pričakovala, da jima bo mentor bolj prijatelj oziroma da je šolo poznal, saj jo je obiskoval in je v njegovem domačem kraju, mentor pa je bil njegov učitelj.

$\mathrm{Na}$ podlagi prikazanih rezultatov lahko domnevo, da so učitelji začetniki od mentorja pričakovali, da jim bo pomagal pri spoznavanju dela učitelja slovenščine in da jih bo opozoril na "pasti« oziroma težave pri poučevanju, potrdimo, saj sta ta dva odgovora najpogostejša, poleg njiju pa je drugi najpogostejši še odgovor »Pričakoval sem, da bo mentor z mano delil svoje izkušnje«. Podobna pričakovanja do mentorja so navedli tudi učitelji začetniki v prej omenjeni raziskavi M. Valenčič Zuljan idr., in sicer so izpostavili pomen mentorjeve pomoči (zlasti strokovne pri opravljanju pripravništva, svetovanje, uvedbo v poklic in seznanitev z delom), kot na primer skupno načrtovanje in analiza nastopov, opozarjanje na napake, posredovanje praktičnih nasvetov in izkušenj, pomoč pri iskanju literature in podobno (2006: 142).

\section{Tabela ı: Ocena sodelovanja z mentorjem}

\begin{tabular}{lcc}
\multicolumn{1}{l}{ Ocena sodelovanja } & $\mathrm{f}$ & $\mathrm{f} \%$ \\
\hline Odlično. & 14 & 19,4 \\
\hline Dobro. & 13 & 18,1 \\
\hline Slabo. & 3 & 4,2 \\
\hline Brez odgovora & 42 & 58,3 \\
\hline Skupaj & 72 & 100,0 \\
\hline
\end{tabular}

Anketirani učitelji začetniki so svoje sodelovanje $\mathrm{z}$ mentorjem ocenili kot odlično (14 oziroma 19,4\%) oziroma dobro (13 oziroma 18,1 \%). Le 3 pri- 
pravniki (4,2 \%) so sodelovanje $\mathrm{z}$ mentorjem ocenili kot slabo. Na to vprašanje več kot polovica anketiranih (42 oziroma 58,3 \%) ni odgovorila, tako da je ocena sodelovanja $\mathrm{z}$ mentorjem nekoliko pomanjkljiva. Zaradi tega standardnega odklona nismo računali.

Našo domnevo, da učitelji začetniki njihovo sodelovanje $\mathrm{z}$ mentorjem ocenjujejo kot dobro, lahko torej z manjšim zadržkom potrdimo, saj so pripravniki v povprečju ocenili njihovo sodelovanje $\mathrm{z}$ mentorjem odlično/dobro. Takšen rezultat je spodbuden, saj tudi stroka (na primer Mullen, 2012, Valenčič Zuljan idr., 2007a) izpostavlja pomen kakovostnega medosebnega odnosa med mentorjem in mentorirancem, ki naj vključuje zaupanje in spoštovanje (primer Mass Mentoring Partnership, 2013).

\section{Učitelji začetniki o usposobljenosti mentorja za opravljanje nalog mentorja}

Učitelje začetnike smo povprašali tudi, kako ocenjujejo usposobljenost mentorja za opravljanje nalog mentorja, torej mentorja kot modela, vključevalca v šolsko kulturo, sponzorja, podpornika in izobraževalca. Njihove ocene so prikazane v Tabeli 11.

\section{Tabela II: Ocena usposobljenosti mentorja za opravljanje nalog mentorja}

\begin{tabular}{lcc}
\hline \multicolumn{1}{l}{ Ocena usposobljenosti mentorja } & $\mathrm{f}$ & $\mathrm{f} \%$ \\
\hline Odlično. & 16 & 22,2 \\
\hline Dobro. & 9 & 12,5 \\
\hline Slabo. & 4 & 5,6 \\
\hline Brez odgovora & 43 & 59,7 \\
\hline Skupaj & 72 & 100,0
\end{tabular}

Med ocenami anketiranih učiteljev začetnikov glede usposobljenosti mentorja za opravljanje ključnih nalog in vlog mentorja učitelju začetniku prevladuje odlična (16 oziroma $22,2 \%$ ) oziroma dobra ( 9 oziroma $12,5 \%$ ) ocena, 4 učitelji začetniki $(5,6 \%)$ pa so jo ocenili kot slabo. Tudi na to vprašanje večina učiteljev začetnikov (43 oziroma 59,7 \%) ni odgovorila, zato je tudi ta ocena pomanjkljiva in zaradi tega tudi standardnega odklona nismo računali. 
Našo predpostavko, da učitelji začetniki usposobljenost svojega mentorja za opravljanje ključnih nalog, ki jih imajo mentorji v času pripravništva, ocenjujejo z oceno dobro, lahko potrdimo z zadržkom, saj na vprašanje dobra polovica anketiranih v vzorcu ni odgovorila. Naši rezultati so podobni rezultatom raziskave $M$. Valenčič Zuljan idr., ki je ugotovila, da »so po mnenju pripravnikov mentorji v povprečju dobro usposobljeni za posamezne naloge, ki jih imajo v času mentorstva pripravniku« (2007b: 55 ). Podobno pa je ugotovila še ena slovenska raziskava (Javrh, 2007), in sicer so učitelji novinci navedli, da so imeli dobrega mentorja, ki jih je uvajal v poklic in spretnosti, ki jih med formalnim izobraževanjem niso mogli pridobiti.

\section{Učitelji začetniki o mentorjevi profesionalni kompetenci za poučevanje slovenščine}

Mentor je učitelju začetniku model poučevanja, zato mora imeti poleg sposobnosti za opravljanje vloge mentorja, razvite tudi ustrezne strokovne kompetence. Učitelji začetniki so ocenili tudi mentorjeve profesionalne kompetence. Njihove ocene posameznih vrst kompetenc so prikazane v Tabeli 12.

Tabela ı2: Ocena mentorjeve profesionalne kompetence

\begin{tabular}{|c|c|c|c|c|c|c|c|c|}
\hline \multirow{3}{*}{ Vrsta kompetence } & \multicolumn{6}{|c|}{ Ocena kompetence } & \multicolumn{2}{|c|}{ Skupaj } \\
\hline & \multicolumn{2}{|c|}{ Odlično } & \multicolumn{2}{|c|}{ Dobro } & \multicolumn{2}{|c|}{ Slabo } & \multirow{2}{*}{$\mathrm{f}$} & \multirow{2}{*}{$\mathrm{f} \%$} \\
\hline & f & $\mathrm{f} \%$ & $\mathrm{f}$ & $\mathrm{f} \%$ & $\mathrm{f}$ & $\mathrm{f} \%$ & & \\
\hline Literarnostrokovna kompetenca. & 22 & 73,3 & 7 & 23,3 & 1 & 3,3 & 30 & $100,0^{*}$ \\
\hline Jezikoslovna kompetenca. & 19 & 63,3 & 10 & 33,3 & 1 & 3,3 & 30 & $100,0^{*}$ \\
\hline $\begin{array}{l}\text { Splošna pedagoška kompetenca } \\
\text { za organizacijo in vodenje pouka. }\end{array}$ & 21 & 70,0 & 7 & 23,3 & 2 & 6,7 & 30 & 100,0 \\
\hline $\begin{array}{l}\text { Jezikovnodidaktična kompeten- } \\
\text { ca za poučevanje jezika. }\end{array}$ & 18 & 60,0 & 11 & 36,7 & 1 & 3,3 & 30 & 100,0 \\
\hline $\begin{array}{l}\text { Književnodidaktična kompeten- } \\
\text { ca za poučevanje književnosti. }\end{array}$ & 21 & 70,0 & 8 & 26,7 & 1 & 3,3 & 30 & 100,0 \\
\hline $\begin{array}{l}\text { Kompetenca za razvijanje ključ- } \\
\text { nih zmožnosti. }\end{array}$ & 19 & 63,3 & 8 & 26,7 & 3 & 10,0 & 30 & 100,0 \\
\hline
\end{tabular}

*Zaradi zaokroževanja vsota strukturnih odstotkov ni ıoo,o, ampak 99,9.

Od 72 anketiranih učiteljev začetnikov je mentorjeve profesionalne kompetence ocenilo le $30(41,7 \%)$ anketirancev. Od teh je mentorjevo literarnostrokovno kompetenco slabe tri četrtine učiteljev začetnikov (22 ozi- 
roma $73,3 \%)$ ocenilo kot odlično, $7(23,3 \%)$ dobro in $1(3,3 \%)$ kot slabo. Jezikoslovno kompetenco jih je 19 (63,3\%) ocenilo odlično, 10 (33,3 \%) dobro in $1(3,1 \%)$ slabo. 21 anketirancev (70,0 \%) je splošno pedagoško kompetenco mentorjev za organizacijo in vodenje pouka ocenilo kot odlično, 7 (23,3 $\%)$ dobro in $2(6,7 \%)$ slabo. Kot odlično je jezikovnodidaktično kompetenco mentorjev za poučevanje jezika ocenilo 18 učiteljev začetnikov (6o,o \%), kot dobro $11(36,7 \%)$ in kot slabo 1 (3,3 \%). Tudi književnodidaktično kompetenco mentorjev za poučevanje književnosti je kar 21 anketiranih učiteljev začetnikov (7o,o \%) ocenilo odlično, 8 (26,7 \%) dobro in 1 (3,3\%) slabo. Mentorjevo kompetenco za razvijanje ključnih zmožnosti jo je $\mathrm{z}$ odlično oceno ocenilo 19 (63,3\%), z dobro $8(16,7 \%)$ in slabo 3 učitelji začetniki (10,o $\%)$.

$S$ pomočjo prikazanih rezultatov lahko našo domnevo, da učitelji začetniki mentorjeve profesionalne kompetence ocenjujejo kot odlične, zaradi nizkega odstotka odgovorov potrdimo $\mathrm{z}$ manjšim zadržkom. V povprečju so učitelji začetniki vse profesionalne kompetence mentorjev ocenili $\mathrm{z}$ odlično oceno, $\mathrm{z}$ najvišjim odstotkom odličnih ocen literarnostrokovno kompetenco, ki ji sledita splošna pedagoška kompetenca za organizacijo in vodenje pouka ter književnodidaktična kompetenca za poučevanje književnosti.

\section{Sklep}

V procesu oblikovanja poklicne identitete učitelja začetnika je bistvenega pomena ustrezna socialna podpora, ki so je deležni zlasti od svojih mentorjev, in njihov dinamičen odnos znotraj referenčne skupine, ki jo prav tako predstavlja mentor. Stroka velik vpliv pripisuje še opazovanju šolske prakse, torej poučevanju mentorja, in izkušnje v prvem letu poučevanja, ki ga predstavlja ravno obdobje uvajanja $\mathrm{v}$ pedagoški poklic (pripravništva).

Učitelji začetniki so $\mathrm{v}$ raziskavi njihov odnos $\mathrm{z}$ mentorjem ocenili kot dober in prav tako mentorje ocenjujejo kot kompetentne za opravljanje nalog mentorja. Njihova začetna pričakovanja do mentorja so se nanašala zlasti na delo učitelja slovenščine, torej didaktično izvedbo pouka, težave pri poučevanju in deljenje (poučevalnih) izkušenj nasploh. So pa učitelji začetniki na splošno videli mentorja bolj kot človeško, kolegialno kakor didaktično oporo, saj so navajali, da so bili na večino vidikov pri pripravi na pouk pozorni na lastno pobudo (več o tem v Šebjanič Oražem, 2016). 


\section{Literatura}

Bela knjiga o vzgoji in izobraževanju v Republiki Sloveniji. Ljubljana: Zavod Republike Slovenije za šolstvo, 2011.

Javornik Krečič, Marija. Pomen učiteljevega profesionalnega razvoja za pouk. Ljubljana: i2 založba, 2008.

Javrh, Petra. »Fazni model razvoja kariere slovenskih učiteljev«. Sodobna pedagogika 58, št. 5 (2007): 68-87.

Koki, Stan. »The Role of Teacher Mentoring in Educational Reform«. V PREL Briefing Paper. Pacific Resources for Education and Learning (ZDA: Office of Educational Research and Improvement, 1997), 1-6.

Mass Mentoring Partnership. Mentoring 101 Train the Trainer Curriculum, Roles and Tasks of a Mentor, 2013. Https://www.uwb.edu/getattachment/ premajor/atp/faculty-and-staff-mentors/mentor-resources/ATP-Mentorship-Program-Roles-and-Tasks.pdf (2. 12. 2019).

Mullen, Carol A. Mentoring: An Overview. V SAGE Handbook of Mentoring and Coaching in Education (London: SAGE Publications Ltd, 2012), 7-23.

Muršak, Janko idr. Poklicni razvoj učiteljev. Ljubljana: Znanstvena založba Filozofske fakultete, 2011.

Parker-Katz, Michelle, in Bay, Mary. »Conceptualizing mentor knowledge: Learning from the insiders«. Teaching and Teacher Education 24 (2008): 1259-1269.

Peklaj, Cirila, idr. Učiteljske kompetence in doseganje vzgojno-izobraževalnih ciljev $v$ šoli. Ljubljana: Znanstvena založba Filozofske fakultete, 2009.

Puklek Levpušček, Melita (2007). Kompetence učiteljev - mentorjev študentov. V Mentorstvo in profesionalna rast učiteljev (Ljubljana: Center za pedagoško izobraževanje Filozofske fakultete, 2007), 49-57.

Razdevšek Pučko, Cveta, in Juriševič, Mojca. »Razvoj poklicne identitete učiteljev«. Vzgoja in izobraževanje 41, št. 6 (2010): 13-19.

Rebolj, Barbara. Vloga učitelja praktika kot mentorja pri pedagoški praksi. V Teorija in praksa v izobraževanju učiteljev (Ljubljana: Center za pedagoško izobraževanje Filozofske fakultete, 2006), 165-172.

Supporting teacher competence development for better learning outcomes. Bruselj: European Commission, Education and Training (Thematic Working Group »Teacher Professional Development«), 2013. Http://ec.europa. eu/assets/eac/education/experts-groups/2011-2013/teacher/teachercomp_ en.pdf (2.12. 2019). 
Šebjanič, Maja. »Pripravništvo profesorjev slovenščine v Sloveniji in Avstriji«. Jezik in slovstvo 59, št. 1 (2014): 83-95.

Šebjanič Oražem, Maja. Vloga obdobja pripravništva pri pridobivanju kompetenc za poučevanje slovenščine: doktorska disertacija. Mentorica Boža Krakar Vogel. Ljubljana: Filozofska fakulteta, 2016.

Valenčič Zuljan, Milena. »Modeli in načela učiteljevega profesionalnega razvoja«. Sodobna pedagogika 52, št. 2 (2001): 122-141.

Valenčič Zuljan, Milena, idr. Učitelj mentor v sistemu pripravništva. Ljubljana: Pedagoška fakulteta, 2006.

Valenčič Zuljan, Milena, idr. Izzivi mentorstva. Ljubljana: Pedagoška fakulteta, $2007 a$.

Valenčič Zuljan, Milena, idr. Spodbujanje profesionalnega razvoja učiteljev pripravnikov: priročnik. Ljubljana: Pedagoška fakulteta in Ministrstvo za šolstvo in šport, $2007 \mathrm{~b}$.

Valenčič Zuljan, Milena, idr. Sistemski vidiki izobraževanja pedagoških delavcev. Ljubljana: Pedagoški inštitut, 2011.

Zelena knjiga o izobraževanju učiteljev $v$ Evropi: kakovostno izobraževanje učiteljev za kakovost $v$ vzgoji, izobraževanju in usposabljanju: tematsko omrežje za izobraževanje učiteljev. Ljubljana: Ministrstvo za šolstvo, znanost in šport, 2001.

Viri

Pravilnik o pripravništvu strokovnih delavcev na področju vzgoje in izobraževanja. Uradni list RS, št. 23/2006. Http://www.uradni-list.si/1/objava.jsp?urlid=200623\&stevilka=901 (2.12. 2019). 